Cadernos de História, Belo Horizonte, v. 22, n. 36, Junho de 2021

DOI: https://doi.org/10.5752/P.2237-8871.2021v22n36p184-205

\section{A proposta de Centros de EDUCAÇÃo E RECREAÇÃO NO MUNICÍPIO DE ARARAQUARA: UMA HISTÓRIA DE AVANÇOS E CONTRADIÇÕES}

Nayane Moreno Perea

Universidade Federal de São Carlos nayanemp@hotmail.com

GÉssica Priscila Ramos

Universidade Federal de São Carlos

gessicaramos@ufscar.br

\title{
Resumo
}

Este artigo resgata a trajetória da educação infantil do município de Araraquara-SP, com destaque para a construção da proposta de Centros de Educação e Recreação (CER). Por meio de pesquisa bibliográfica com suporte documental, buscou-se compreender as contribuições dessa proposta no âmbito da educação infantil. Para tanto, foram definidas como categorias de conteúdo: aspectos históricos, aspectos teóricos e pedagógicos e aspectos organizacionais. Observou-se no estudo que as ações realizadas na educação infantil pelo poder público municipal revelam certo pioneirismo quanto ao reconhecimento do cuidar e do educar sob uma perspectiva integradora e pedagógica ao longo de sua história. Tal processo envolveu orientação curricular de seus professores e agentes educacionais em termos teórico, prático e metodológico, bem como a definição de uma arquitetura efetivamente planejada para a realização de atividades educacionais com crianças de 0 a 5 anos de idade. Não obstante, muito da regulamentação do funcionamento e atendimento dos CER volta-se para o atendimento das necessidades da mãe trabalhadora, bem como apresenta profissionais com diferentes formações segundo a faixa etária da criança atendida, denotando, para além de uma história de muitos avanços, algumas contradições.

Palavras-chave: História da Educação. Educação Infantil. Município.

Recebido em 12 de fevereiro de 2021.

Aprovado em 13 de março de 2021. 
Cadernos de História, Belo Horizonte, v. 22, n. 36, Junho de 2021

DOI: https://doi.org/10.5752/P.2237-8871.2021v22n36p184-205

\title{
The Education AND RECREATION CENTERS PROPOSAL IN THE ARARAQUARA CITY-SP: A HISTORY OF ADVANCES AND CONTRADICTIONS
}

Nayane Moreno Perea

Universidade Federal de São Carlos nayanemp@hotmail.com

GÉssica Priscila Ramos

Universidade Federal de São Carlos

gessicaramos@ufscar.br

\begin{abstract}
This article rescues the trajectory of early childhood education in the municipality of AraraquaraSP, with emphasis on the construction of the proposal for Education and Recreation Centers (CER). Through bibliographic research with documentary support, we sought to understand the contributions of this proposal in the context of early childhood education. For this, content categories were defined: historical aspects, theoretical and pedagogical aspects and organizational aspects. It was observed in the study that the actions carried out in early childhood education by the municipal government reveal a pioneering spirit regarding the recognition of caring and educating from an integrative and pedagogical perspective throughout its history. This process involved the curricular guidance of their teachers and educational agents in theoretical, practical and methodological terms, as well as the definition of an architecture effectively planned for carrying out educational activities with children from 0 to 5 years old. Notwithstanding, much of the regulation of the functioning and attendance of RECs is aimed at meeting the needs of the working mother, as well as presenting professionals with different backgrounds according to the age of the child served, showing, in addition to a history of many advances, some contradictions.
\end{abstract}

Keywords: History of Education. Child education. City. 


\section{INTRODUÇÃo}

$\mathrm{O}$ atendimento educacional das crianças no município de Araraquara teve seu início em 1941 - apesar de sua fundação em 1817 -, sendo um dos primeiros locais do Estado de São Paulo a atuar na área. Nesses 80 anos de história de atuação na educação infantil, o município destaca-se por ter uma das redes mais bem estruturadas da região e pelo seu pioneirismo no setor, sobretudo com a criação dos chamados Centros de Educação e Recreação - CER - (MASCIOLI, 2012), criados em 1971, para o atendimento integral ou parcial de crianças pequenas.

O CER é uma unidade de educação infantil mantida pela prefeitura e administrada pela Secretaria Municipal de Educação (SME), fazendo parte do Sistema Municipal de Ensino de Araraquara. Desse modo, o Centro é responsável pelo atendimento das crianças de 0 a 05 anos de idade residentes no município, integrando creche e pré-escola numa perspectiva educacional segundo sua interpretação, ao entendê-la como "espaço privilegiado [CER] de execução do processo educativo”. (ARARAQUARA, 2011).

Atualmente o município conta com aproximadamente $40 \mathrm{CER}$, tendo como respaldo legal para seu funcionamento a articulação de legislações e de documentos oficiais, como: Constituição Federal Brasileira de 1988, Estatuto da Criança e do Adolescente, Lei de Diretrizes e Bases da Educação de 1996 e Diretrizes Curriculares Nacionais para Educação Infantil. Localmente, a educação infantil ampara-se no Regimento Interno Comum das Escolas Municipais de Educação Infantil, no Manual de Procedimentos, na Proposta Curricular da Pré-Escola, da Recreação e do Berçário e, ainda, cada CER conta com Projeto PolíticoPedagógico. Trata-se de documentos norteadores do atendimento das crianças na educação infantil na rede pública de Araraquara, resultado do esforço local para se dar unidade aos seus Centros.

Com isso, Araraquara apresenta hoje uma rede municipal de educação infantil consolidada no tangente à organização do trabalho pedagógico, do atendimento às crianças e dos espaços, materializada em seus CER. Diante desse contexto, este artigo objetiva resgatar a trajetória da educação infantil do município de Araraquara-SP, com destaque para a construção da proposta de CER. Assim, buscamos compreender tal proposta, tendo como questão de fundo: que contribuição tal experiência traz para o âmbito da educação infantil?

Para tanto, foi realizado levantamento bibliográfico sobre as principais pesquisas sobre o tema no Banco de Teses e Dissertações da CAPES, tendo destaque os seguintes trabalhos: Cavicchia (1993), Assis (2004), Barbosa (2008), Pereira (2008), Mascioli (2012), Diana (2015), Bertochi (2016), Barbosa e Mazzeu (2016), Barbosa e Pimenta (2018). Ainda, foi realizada uma pesquisa documental sobre a educação infantil em Araraquara, notadamente no site Legislação Digital, destacando-se dessa etapa os seguintes documentos: Regimento Comum (ARARAQUARA, 2011), Lei Municipal no 4.938/1997 (ARARAQUARA, 1997), Lei Municipal no 7.863/2013 (ARARAQUARA, 2013) e Ofício SE no 138/2016 (ARARAQUARA, 2016). Para análise dos dados, foram utilizadas as seguintes categorias (KUENZER, 1998): aspectos históricos, aspectos teóricos e pedagógicos e aspectos organizacionais.

Vale destacar que este trabalho integra uma pesquisa maior, cujo objetivo foi, a partir de pesquisa bibliográfica, documental e de campo, identificar e analisar a(s) atual(is) 
concepção(ões) de educação infantil envolvida(s) no Programa Creche Escola, levando em consideração a perspectiva estadual e a perspectiva municipal. No caso deste artigo, conforme indicado anteriormente, suas análises serão embasadas em pesquisa bibliográfica com suporte documental.

\section{AsPeCtos HISTÓRICOS}

O Programa municipal de atendimento das crianças em Araraquara teve seu início aproximadamente há 80 anos por efeito da criação do Parque Infantil Leonor Mendes de Barros, instituído em 1941 - o primeiro no município e um dos primeiros do Estado paulista. (BERTOCHI, 2016; DIANA, 2015; MASCIOLI, 2012; PEREIRA, 2008).

$\mathrm{Na}$ época, cabia ao Departamento de Educação Física e Esportes, da Secretaria de Esportes do Estado, a orientação técnica do Parque Infantil, cujo objetivo repousava no atendimento de crianças com até 07 anos e provenientes de famílias de baixa renda, enquanto seus pais trabalhavam. (BERTOCHI, 2016; DIANA, 2015; MASCIOLI, 2012; PEREIRA, 2008; ASSIS, 2004). Basicamente, sua ação consistia em promover o acolhimento dessas crianças, organizando-as em grupos numerosos e heterogêneos e oferecendo-lhes formas alternativas de recreação mediante a atuação de professores e profissionais nem sempre habilitados. (DIANA, 2015; ASSIS, 2004). Em paralelo a esse tipo de atendimento, o Parque também recebia crianças entre 07 e 13 anos de idade no período alternado. (BERTOCHI, 2016; DIANA, 2015; MASCIOLI, 2012).

Em moldes equivalentes ao primeiro Parque, foram construídos o Parque Infantil Carmelita Garcez e o Parque Infantil Eloá do Valle Quadros, somente e respectivamente em 1951 e em 1969. (BERTOCHI, 2016; DIANA, 2015; MASCIOLI, 2012; PEREIRA, 2008). De acordo com Barbosa e Pimenta (2018, p.148), os Parques Infantis araraquarenses "foram construídos em regiões estratégicas tendo em vista a assistência em diversas modalidades: médica, nutricional, recreativa e educacional com ênfase nas duas primeiras”, o que muito se coaduna com o tipo de preocupação oficial assistencial que pairava em relação à criança brasileira no período. (VIEIRA, 1988).

A necessidade de ampliação do atendimento infantil fez-se presente durante a década de 1970. Barbosa e Pimenta (2018) atribuem tal necessidade às mudanças do contexto municipal mais amplo decorrente do crescimento acentuado da população somado ao desenvolvimento da indústria e agricultura que passou a requerer mão de obra feminina. Esse movimento de impulsão do atendimento infantil em resposta à demanda cada vez maior do trabalho feminino também estava presente na realidade nacional, mas, comparativamente, a história municipal guardava certas peculiaridades:

\footnotetext{
Enquanto nacionalmente se buscava aperfeiçoar os espaços de guarda e assistência às crianças, em Araraquara se concebia, ainda que preliminarmente, instituições de caráter educativo, culminando na criação dos Centros de Educação e Recreação vinculados à antiga Diretoria de Educação e Cultura do Departamento de Educação, Cultura, Saúde e Promoção Social e não no Departamento de Bem-Estar Social ou Secretaria de Ação Social, como era frequente em outros municípios. (BARBOSA; PIMENTA, 2018, p. 148, grifos nossos).
} 
O referido Departamento de Educação, Cultura, Saúde e Promoção Social, criado no âmbito de uma nova estrutura administrativa em 1971, tinha como órgão vinculado à Diretoria de Educação e Cultura (DIANA, 2015; ASSIS, 2004) voltado totalmente à educação (PEREIRA, 2008, p. 31), ponto em que reside a peculiaridade de Araraquara.

Nesse cenário, a atuação da Diretoria atribuiu ao atendimento das crianças nas classes pré-primárias a função preparatória para o ensino primário, propiciando um processo de mudança da educação infantil de Araraquara. (ASSIS, 2004). A instalação do Parque Infantil Dona Cotinha de Barros em 1971 é bastante elucidativa, vez que contava de forma inovadora com classes de pré-primário para o atendimento específico de crianças com 06 anos, cujo propósito era prepará-las para o ingresso na escola primária. (BERTOCHI, 2016; DIANA, 2015; MASCIOLI, 2012). Segundo Bertochi (2016), os professores responsáveis pelas novas classes eram habilitados em educação pré-primária.

Aliado a isso, ainda em 1971, os Parques Infantis de Araraquara foram estruturalmente readaptados com a ampliação de equipamentos educacionais (MASCIOLI, 2012) e renomeados como Centros de Educação e Recreação (CER), de modo a enfatizar sua vinculação educacional. À vista disso, Diana (2015, p. 41) afirma que os antigos Parques Infantis foram os precursores dos CER no município de Araraquara, instituições responsáveis pelo Programa municipal de educação infantil até a atualidade.

Sob a ótica do CER, as crianças foram divididas em grupos pelo critério das faixas etárias e suas especificidades (03, 04, 05 e 06 anos) e, ainda, de 1982 em diante passaram a incluir o atendimento de crianças de 0 a 03 anos por meio dos berçários. (MASCIOLI, 2012; PEREIRA, 2008). Dessa monta, os primeiros Parques infantis, que passaram a ser os CER mais antigos, não atendiam o berçário, dada a impossibilidade de alteração de suas plantas originais (CAVICCHIA, 1993; ASSIS, 2004), visto que tais prédios eram tombados como patrimônio histórico da cidade. (ASSIS, 2004).

A inclusão dos berçários nas novas unidades dos CER representou o início da pioneira integração da creche e pré-escola (ASSIS, 2004), como também a priorização da ampliação dos atendimentos desde a tenra idade. (CAVICCHIA, 1993). A integração creche e pré-escola na mesma unidade de educação infantil é considerada, pelo próprio município, como pioneira (DIANA, 2015), contrapondo-se a uma realidade nacional predominantemente dicotômica que as assolavam.

Apesar disso, havia diferenciações entre creche e pré-escola no interior dessas instituições assentadas na ênfase dada, em maior ou menor grau, ao caráter educacional nesses atendimentos: enquanto na pré-escola, havia professores habilitados para a educação pré-primária, os berçários ficavam sob responsabilidade das pajens, não habilitadas, as quais tinham muitas vezes apenas o primeiro grau. (CAVICCHIA, 1993; ASSIS, 2004).

Nessa reorganização, os CER, tal qual nos dias atuais, passaram a oferecer três modalidades de atendimento: berçário, para crianças menores de 03 anos; pré-escola, para crianças de 03 a 06 anos; recreação, para crianças de 03 a 06 anos atendidas em período integral. (BARBOSA; PIMENTA, 2018). Percebemos, assim, que a pré-escola ainda - mesmo na organização peculiar de Araraquara - denotava um caráter educacional diferenciado se comparado ao atendimento oferecido aos berçários, muito mais preocupado com os cuidados propriamente ditos. Corrobora tal afirmação o fato de que a pré-escola se orientava didática e 
pedagogicamente pela chamada Proposta Curricular para a Educação Pré-Escolar, elaborada pela Coordenadoria de Estudos e Normas Pedagógicas (CENP), da Secretaria do Estado de São Paulo. (MASCIOLI, 2012; PEREIRA, 2008; BARBOSA; PIMENTA, 2018). Tal proposta foi introduzida nos CER na forma de orientações técnicas a partir de 1977 (MASCIOLI, 2012; PEREIRA, 2008) até 1983, segundo Cavicchia (1993). Enquanto isso, os berçários dos CER, além de serem inspirados em modelos hospitalares, organizavam-se por meio do Manual de Orientação de Responsabilidade dos Departamentos de Saúde e Educação, de modo que o treinamento das berçaristas era estruturado a partir deste. (CAVICCHIA, 1993).

As autoras Barbosa e Pimenta (2018) afirmam que, em Araraquara, embora fosse prevista de forma pioneira o atendimento às crianças menores de 06 anos antes mesmo da promulgação da CF/88 (BRASIL, 1988), "observava-se a permanência da ênfase em atividades rotineiras", contribuindo para configuração de "uma estrutura e funcionamento higienista e ao mesmo tempo assistencialista, dissidente daquele caráter educativo anunciado por ocasião da criação dos CERs" (BARBOSA; PIMENTA, 2018, p. 148-149), mas muito coerente nacionalmente, se considerada a sua tendência no atendimento à infância. Nesse sentido, o que notamos é que a história da educação infantil em Araraquara mostra-se, às vezes, alguns passos à frente em face à tendência nacional de atendimento à criança pequena, mas, em outros, revela-se alinhada aos mesmos preceitos, paradoxalmente entre a "luz" e a "sombra", conforme trabalhado no artigo de Barbosa e Pimenta (2018).

Os conceitos metafóricos "luz" e "sombra" foram desenvolvidos pelas autoras Barbosa e Pimenta (2018) no artigo sobre o processo histórico de constituição dos preceitos curriculares da educação infantil em Araraquara. Tais conceitos ajudam a entender que, embora a educação infantil de Araraquara apresente especificidades e avanços frente à história da educação infantil nacional, ela, muitas vezes, partilha de suas contradições e ocultações. Por exemplo: enquanto no Brasil a busca era por "aperfeiçoar os espaços de guarda e assistência às crianças, em Araraquara se concebia”, de modo preliminar, "instituições de caráter educativo, culminando na criação dos Centros de Educação e Recreação”. (BARBOSA, PIMENTA, 2018, p. 148). As sombras e contradições são decorrentes:

\footnotetext{
[...] de fases predominantes de desarticulação entre os pressupostos teórico-práticos anunciados nos documentos ou propostas curriculares e sua materialização nas práticas, ausência de políticas consistentes de investimentos em formação continuada, fiscalização e financiamento e ainda, a insuficiência de concepções naturalizantes e assistencialistas comuns a diversas redes brasileiras. Procura-se na luz o que se deixa ocultar nas sombras, ou seja, em consonância com a contradição própria do movimento histórico, embora reconheçamos reiteradamente a necessidade de rever as concepções sobre os currículos para a infância, tal revisão nem sempre se faz acompanhada de ações a longo prazo que vinculem efetivamente o discurso e as práticas. Essa ocultação se acentua ainda mais quando as ações de revisão dos pressupostos curriculares ocorrem para cumprir agendas externas de âmbitos estaduais e federais. (BARBOSA, PIMENTA, 2018, p. 148, grifos nossos).
}

Na posição das autoras, a "luz" serviria para clarificar onde há "sombra" na história da educação infantil em Araraquara (em continuidades com a história nacional), bem como para pensarmos a educação infantil doravante.

Nesse caminho, podemos afirmar que a década de 1980 se destaca na história da educação infantil em Araraquara em virtude das novas unidades criadas, tendo como diferencial o seu 
surgimento no interior do Departamento de Educação e Cultura e com atendimento conjunto de creches e pré-escolas, como dito. Diana (2015) e Pereira (2008) apontam que somente em maio de 1982, por exemplo, houve a criação de 5 CER para atendimento de crianças de 0 a 06 anos. Atrelada a essa expansão da educação infantil araraquarense no período, tem-se como plano de fundo a organização do documento Programa de Educação em 1983, a fim de identificar a educação municipal e delinear diretrizes e objetivos. (BERTOCHI, 2016, p. 45). De acordo com a Bertochi (2016), a elaboração de tal documento contou com uma comissão convocada pelo então prefeito Clodoaldo Medina (1983-1988) com a seguinte composição: profissionais da Diretoria de Educação e Cultura do município, professores da UNESP, diretores e professores dos CER e comunidade.

A proposta do Programa residia na promoção de condições melhores de vida das pessoas mais carentes por meio de atendimento integrado entre as áreas de saúde, educação e promoção social, especialmente às crianças de 0 a 06 anos. (ASSIS, 2004; CAVICCHIA, 1993). Pretendia-se, desse modo, expandir o atendimento infantil pelo chamado Cinturão SaúdeEducação nos bairros periféricos de Araraquara (BARBOSA; PIMENTA, 2018), concretizado pela construção de CER e de Centros de Saúde lado a lado. (CAVICCHIA, 1993; ASSIS, 2004; MASCIOLI, 2012; BERTOCHI, 2016; BARBOSA; PIMENTA, 2018). Tal proximidade servia como forma de beneficiar tanto as crianças como a população carente circunscrita naquelas localidades (CAVICCHIA, 1993). "Na vigência desse programa, foram construídos mais de dez CER e iniciou-se um programa de formação continuada e foi dado um treinamento para adequação do pessoal à nova proposta de trabalho”. (ASSIS, 2004, p. 72).

Diante disso, não podemos deixar de evidenciar certo alinhamento dessa postura municipal à tendência nacional concentrada em modelos de compensação das carências da criança pobre (ROSEMBERG, 1999), os quais pretensamente se elevaram ao patamar de solução dos males sociais, quando o seu objetivo era melhorar as condições de vida da população carente do município pelo estreitamento da relação saúde-educação. Nada obstante, Barbosa e Pimenta (2018, p. 149) ponderam que, paradoxalmente, a integração dos CER com os Centros de Saúde "se constitui como vetor para sinalizar as especificidades de atendimento dos equipamentos de educação e saúde", de modo que não houve uma supressão dos aspectos pedagógicos pelos aspectos higienistas.

Paralelamente, ocorreu o estabelecimento de uma parceria do poder público com docentes da UNESP e, como resultado, foi criada a primeira equipe técnica multidisciplinar em 1986, vinculada ao Departamento de Educação e Cultura. Essa equipe, composta por pedagogo, psicólogo, coordenador, nutricionista e assistente social, tinha como função "organizar programas de capacitação continuada, de avaliação e de reorientação curricular". (BARBOSA; PIMENTA, 2018, p. 149). Em 1992, a equipe técnica foi renomeada como Coordenadoria Técnica de Programa de Educação (ASSIS, 2004; MASCIOLI, 2012), de modo que "suas ações se orientam prioritariamente para produzir um diagnóstico e análise da identidade, perfil e atuação pedagógica dos profissionais dos CERs”. (BARBOSA; PIMENTA, 2018, p. 149). Segundo as autoras, os resultados desse trabalho serviram como base para a elaboração de um novo currículo para o atendimento das modalidades abrigadas nos CER, como se abordará adiante.

As sistemáticas discussões, análises, bem como as proposições viabilizadas tanto 
pela parceria prefeitura-universidade como pela formação da predita equipe técnica, fizeram prosperar o programa de intervenção educacional para os CER sob o referencial piagetiano na década de 1990, com a participação principal da professora doutora Durlei de Carvalho Cavicchia, do campus da UNESP de Araraquara. De acordo com ela, a proposta era criar condições que favorecessem o desenvolvimento infantil desde os primeiros anos de vida, conscientizando os educadores e orientando suas ações pedagógicas nesse sentido, notadamente num contexto preocupado em prevenir o desenvolvimento atrasado de crianças de famílias de baixa renda (CAVICCHIA, 1993) - ideia compensatória presente no município e no âmbito nacional.

Nessa perspectiva, o eixo norteador da proposta era o desenvolvimento integral e harmonioso das potencialidades da criança, sendo necessário o envolvimento na ação pedagógica do cuidado-educação-desenvolvimento, em que se valorizasse a interação da criança com as outras crianças, os adultos e o ambiente físico, como também o fortalecimento da consciência da influência formativa dos professores e educadores sobre o seu desenvolvimento (CAVICCHIA, 1993). Assim, colocava-se quase que exclusivamente o desenvolvimento da criança na educação infantil como ponto de partida e de chegada.

A proposta de formação continuada dos profissionais pretendia alterar as práticas cotidianas a partir do referencial construtivista em voga, de modo que fosse "coerente com as concepções desses educadores sobre educação, o significado da infância e o papel da instituição educacional no processo de desenvolvimento da criança”. (GOMES, 1996, p. 34). Para isso, utilizou-se:

[...] de recursos diversificados de formação, como reuniões, registros em vídeo-tape ou anotações das ocorrências dos CERs, juntamente com a presença constante da equipe técnica no cotidiano das ações nas unidades, os organizadores do curso observam resultados satisfatórios quanto a identidade do educador da creche/pré-escola e a formação e o funcionamento da equipe de trabalho (Cavicchia, 1994). (GOMES, 1996, p. 34).

Como exemplo desses resultados, Cavicchia (1993) aponta a desvinculação das agentes educacionais - na época, chamadas de berçaristas -, da visão de mãe substituta, citada por elas mesmas.

Dado o objetivo de avaliar o atendimento e realizar um trabalho de formação em serviço mais direcionado (ASSIS, 2004), a primeira versão do Manual de Procedimentos dos CER foi publicada em 1994 pela SME, com a natureza de orientar os trabalhos outrora desenvolvidos naqueles Centros. O referido Manual foi elaborado "sob a coordenação da equipe técnica a Rede Municipal [que] organizou com a participação de todos os grupos de profissionais da já então Secretaria Municipal de Educação", constituindo num "instrumento organizador das práticas educativas em sua dimensão mais propriamente técnico-administrativa”. (BARBOSA, PIMENTA, 2018, p. 149). Mesmo com esse viés, ele foi produzido "tangenciado pelo intenso debate no campo acadêmico sintetizado na defesa da urgente consolidação do caráter educativo como dinamizador das propostas curriculares para a educação da infância”. (BARBOSA; PIMENTA, 2018, p. 149).

Esse e outros documentos elaborados pretendiam também dar um sentido de rede, isto é, de unidade entres os CER (DIANA, 2015), o que, frente às múltiplas e díspares formas de atendimento instaladas em nível nacional, também pode ser interpretado como uma 
peculiaridade do município de Araraquara. Nesse sentido, podemos citar, a partir de Barbosa e Pimenta (2018, p. 150), as Diretrizes Pedagógicas Municipais de 1997, que "continham os princípios para a reorganização pedagógica dos CERs e as orientações para a construção dos Projetos curriculares das diferentes modalidades de atendimento", com vistas a uma atuação educativa intencional preocupada em possibilitar a construção do conhecimento e desenvolvimento das crianças atendidas. Além disso, temos a aprovação da Lei Municipal no 4938 de 1997 (ARARAQUARA, 1997), por meio da qual se instituiu o Sistema Municipal de Ensino de Araraquara que incluía em si as instituições municipais de educação infantil (MASCIOLI, 2012), em consonância com as determinações da CF/88 (BRASIL, 1988) e demais legislações desinentes.

Nessa mesma toada, a organização técnica, administrativa e pedagógica da rede municipal de educação infantil de Araraquara também se deu mediante a construção e apresentação de documentos vinculados entre si a partir de 2000, como: os Projetos Curriculares das modalidades atendidas e a segunda versão do Manual de Procedimentos (DIANA, 2015). Tal material tratava-se de uma sistematização das práticas orientadoras do trabalho pedagógico, dos procedimentos e das regras organizadoras da rede desde então. (DIANA, 2015).

Assim, a despeito do pioneirismo de Araraquara na educação infantil e da crescente criação de CER, o poder público municipal engajou-se mais no desenvolvimento do ensino fundamental a partir da década de 1990 (MASCIOLI, 2012), o que não causa estranhamento quando se observa a questão numa perspectiva nacional, influenciada pelas recomendações internacionais para os ditos países subdesenvolvidos de privilegiamento do ensino fundamental, em detrimento do atendimento infantil (ROSEMBERG, 1999). O engajamento maior no ensino fundamental deu-se em prejuízo da expansão quantitativa e qualitativa da educação infantil nos níveis necessários, realidade bastante comum em todo território brasileiro. No contexto particular de Araraquara, tal realidade resultou na forte pressão por parte do Ministério Público (MP) sobre o poder público municipal com o escopo de se efetivar o direito constitucional à educação infantil na cidade (ASSIS, 2004).

A atuação do MP, mais especificamente da Promotoria da Infância e Juventude, concretizou-se no Termo de Ajustamento de Conduta (TAC), pelo qual a prefeitura de Araraquara permaneceu submetida por aproximadamente nove anos (MISSÃO..., 2012). Esse termo foi proposto à prefeitura em 2004 em resposta à situação flagrada de crianças fora dos CER no município de Araraquara. Exigia-se, desse modo, basicamente o fornecimento de vagas em creches e pré-escolas a crianças de até 05 anos. (MISSÃO, 2012; SANTOS, 2016). Enquanto não fossem cumpridas as exigências impostas, o TAC perduraria em face ao município, transmitindo-se entre as administrações e prefeitos. Nesse meandro, o município de Araraquara não correspondeu às exigências do TAC, acarretando, por conseguinte, na sua renovação em 2009. (MISSÃO ，2012).

Frente a esse desafio, a prefeitura de Araraquara conseguiu encerrar o TAC somente em 2012 perante a decisão da promotora da Infância e Juventude da ocasião, que considerou o empenho do poder público na abertura de novas vagas, na construção e ampliação de unidades de educação infantil no município. (MISSÃO, 2012).

As ampliações e construções não foram as únicas medidas tomadas para remediar a dificultosa situação do município. Assis (2004, p. 97-98) revela também como estratégia o 
aumento considerável do número de crianças por turmas dos CER já existentes, sem que fosse acompanhado por aumento de recursos para sua manutenção. Sobre isso, é importante se observar com criticidade o referido processo, considerando que nem sempre a expansão numérica em vagas na educação infantil, significa garantia de qualidade da educação nem para as crianças e nem para os seus profissionais, a exemplo da própria história nacional (ROSEMBERG, 1999, 2002; PRETO, 2016) - em que o baixo investimento governamental resultou em instituições com precaríssimas instalações, poucos recursos (inclusive de alimentos) e materiais pedagógicos, inadequação na formação de pessoal, sucateamento do atendimento, baixa remuneração dos professores, muitas vezes, leigos - bem como da referida estratégia municipal. Não por acaso, os dados colhidos na dissertação de Assis (2004) revelam que as professoras araraquarenses entrevistadas identificaram uma preocupação da SME mais focada na expansão do atendimento em termos quantitativos em detrimento da qualidade.

Ao encontro da situação acima elucidada, Barbosa e Pimenta (2018) identificam um hiato também nas discussões sobre as questões curriculares a partir dos anos 2000, contrariando o próprio contexto municipal "de mais de cinco décadas de intensa mobilização no sentido de manter um pioneirismo na elaboração e implementação de ações e politicas não subordinadas às legendas partidárias que administraram o município" (BARBOSA; PIMENTA, 2018, p. 151, grifos nossos).

\section{Aspectos Teóricos e Pedagógicos}

A SME de Araraquara autorizou a realização de uma pesquisa empírica pela professora Eliza Maria Barbosa nos anos de 2006 e 2007, com o objetivo de fornecer dados a sua tese de doutorado realizada no programa de pós-graduação da UNESP. Tais dados também foram compartilhados com a equipe técnica da SME. A pesquisa consistiu na análise dos elementos pedagógicos e teóricos presentes no trabalho dos professores nos CER investigados e, diante deles, foi defendido pela autora a adesão à Pedagogia Histórico-Crítica e à Psicologia Histórico-Cultural. (BARBOSA; MAZZEU, 2016). Ante os resultados encontrados, Barbosa (2008) identificou na ação pedagógica de tais CER a presença de um psicologismo exacerbado residente nas teorias psicológicas do desenvolvimento, que se entendeu ser resquício do próprio processo histórico da educação infantil em Araraquara, notadamente por meio da parceria entre secretaria e universidade em meados de 1993. Além disso, identificou simultaneamente uma concepção naturalista, cujas bases teóricas centram-se na Pedagogia da Infância, corrente teórica hegemônica no campo da Educação Infantil. (BARBOSA; PIMENTA, 2018).

Segundo a pesquisa em pauta, nas atividades desenvolvidas com as crianças não se verificava "a presença de conteúdos culturais, intencionalmente selecionados para compor as situações de aprendizagem” (BARBOSA, 2008, p. 147), visto que veiculavam: a) a brincadeira como experiência natural e imediata com potencial desenvolvimento da criança, esvaziada em seu aspecto cultural e pedagógico; b) excessiva valorização de atividades de rotina e

de brincadeiras livres, em detrimento dos saberes superiores cientificamente validados; c) o professor como "facilitador de situações educativas ou somente acompanhante do desenvolvimento natural e espontâneo das crianças" (BARBOSA, 2008, p. 113), por meio do 
cumprimento das funções de cuidado, sem conotação educacional e de situações materiais e organizacionais adequadas às condições que potencializem a interação (criança, adultos, ambiente) e o desenvolvimento. De acordo com o referencial teórico crítico defendido na referida pesquisa, tais práticas não levavam em conta "[...] a estreita relação entre o desenvolvimento e aquilo que o promove, as relações de produção de conhecimentos, saberes e técnicas culturais, sem as quais nenhum desenvolvimento humano acontece de forma efetiva" (BARBOSA; MAZZEU, 2016, p. 6288).

Consoante a isso, no ano de 2009, a equipe técnica de Araraquara realizou avaliação informal da educação infantil, constatando "uma profunda estagnação da rede e o caráter difuso das modalidades organizativas do cotidiano das crianças” (BARBOSA; PIMENTA, 2018, p. 151) e ainda que:

\begin{abstract}
[...] as unidades educativas infantis haviam reduzido suas orientações curriculares a conteúdos extraídos de datas comemorativas, por áreas do desenvolvimento, listas de atividades, temas de pesquisa e/ou projetos de trabalho. Além disso, observava-se que atividades como desenhos, textos literários, jogos e brincadeiras dirigidas, já não eram mais praticadas. Lança-se sombras, produz-se dissidências e já não se observa mais intencionalidade nem mesmo nas ações de cuidado. As ações caracterizavam um retorno à concepção assistencialista onde os balizadores são o tempo e o cumprimento das rotinas, em detrimento das necessidades afetivas $\mathrm{e}$ cognitivas das crianças. (BARBOSA; PIMENTA, 2018, p. 151, grifos nossos).
\end{abstract}

A título de síntese, a pesquisa de Barbosa (2008) associada à avaliação da equipe técnica da SME identificavam basicamente: a) falta de interação dos professores nas ações educativas; b) falta de intencionalidade nas atividades propostas pelos professores, sem clareza dos objetivos; c) ações insuficientes frente ao objetivo de desenvolver integralmente as crianças; d) ações de cuidado negligenciando as ações com finalidade educativa. (ARARAQUARA, 2016; BARBOSA; PIMENTA, 2018).

Perante esse panorama da rede municipal, a equipe técnica da SME ponderou necessário repensar a educação infantil numa "tríade: formação docente, práticas educativas intencionais e políticas públicas, dando um papel central para o ensino na educação das crianças pequenas” (BARBOSA; MAZZEU, 2016, p. 6288), tomando como base os referenciais teóricos propostos por Barbosa (2008). Nesse cenário, deu-se início ao processo de reestruturação conceitual (infância, trabalho docente, desenvolvimento infantil, educação infantil), teórica, curricular e metodológica da educação infantil do município de Araraquara, desencadeado por meio da parceria entre SME e a Faculdade de Ciências e Letras da UNESP (FCLAr), representada notadamente pela professora doutora Eliza Maria Barbosa, do departamento de Psicologia da Educação.

A aludida reestruturação teve como motivação o repensar de novas bases curriculares para o trabalho com as crianças da educação infantil, de modo a garantir o seu desenvolvimento integral coerente aos referenciais teóricos indicados, Psicologia Histórico Cultural e Pedagogia Histórico-Crítica. (BARBOSA; MAZZEU, 2016). Nessa perspectiva, concebia-se que o ensino era um motor do desenvolvimento infantil, de modo que a intencionalidade do trabalho pedagógico do professor seria um elemento fundamental. (BARBOSA; MAZZEU, 2016). Nas palavras de Barbosa e Pimenta (2018, p. 147), tratava-se de:

[...] um processo de revisão das práticas assistemáticas reveladas, desencadeando ações prioritárias que articulavam a formação continuada dos professores e educadores, a promoção 
de práticas educativas intencionais e a revisão dos pressupostos teóricos tendo em vista a construção de uma proposta curricular para a rede de Educação Infantil.

$\mathrm{Na}$ qualidade de ações implementadas em favor desse movimento de revisão curricular e da construção teórica, houve a criação do Programa Cresça e Apareça (em 2012) e do Laboratório Pedagógico da Educação Infantil (LAPEI, 2014).

O Cresça e Apareça constituiu-se como programa de formação continuada de professores e educadores da rede municipal de Araraquara no âmbito da educação infantil, de modo a produzir diversas ações no sentido de revisar as concepções teóricas desses profissionais e de apontar a Psicologia Histórico-Cultural e da Pedagogia Histórico-Crítica como "uma alternativa para a consolidação de práticas educativas intencionais que reconhecem no ensino dos conteúdos culturalmente produzidos a premissa de constituição das propriedades tipicamente humanas”. (BARBOSA; PIMENTA, 2018, p. 152).

De acordo com a equipe técnica da educação infantil (ARARAQUARA, 2016, p. 4-5) e com Barbosa e Pimenta (2018), o Programa Cresça e Apareça apresentava as ações expostas no Quadro 1, condensadas com seus respectivos objetivos. 


\section{Quadro 1 - Ações e objetivos do Programa Cresça e Apareça}

\begin{tabular}{|c|c|}
\hline Ações & Objetivos \\
\hline Criação de um grupo de estudos & $\begin{array}{l}\text { - Leitura e apropriação da Psicologia Histórico-Cultural e Pedagogia } \\
\text { Histórico-Crítica; } \\
\text { - Ampliar o nível de conhecimento dos profissionais que atuam na } \\
\text { equipe técnica da educação infantil e que atuarão no LAPEI; } \\
\text { - Desenvolver metodologias associadas à Pedagogia Histórico-Crítica. }\end{array}$ \\
\hline $\begin{array}{l}\text { Criação de uma equipe de pro- } \\
\text { fissionais }\end{array}$ & $\begin{array}{l}\text { - Para atuar no LAPEI como co-formadores dos demais profissionais da } \\
\text { rede, cujos objetivos são: } \\
\text { - Compor o grupo de estudos; } \\
\text { - Elaborar atividades que articulem conteúdo, metodologia e objetivos, } \\
\text { considerando as especificidades do desenvolvimento, os subsídios teó- } \\
\text { ricos e os documentos oficiais municipais; } \\
\text { - Propor atividades para serem realizadas pelos professores da rede, } \\
\text { acompanhando e avaliando sua execução nos CER; } \\
\text { - Orientar e avaliar as atividades propostas pelos professores. }\end{array}$ \\
\hline $\begin{array}{l}\text { Subsídio e acompanhamento do } \\
\text { Horário de Trabalho Pedagógico } \\
\text { Coletivo (HTPC) dos professo- } \\
\text { res nos CER }\end{array}$ & $\begin{array}{l}\text { - Realizar acompanhamento itinerante, oferecendo leituras e sugestões } \\
\text { de atividade a serem desenvolvidas; } \\
\text { - Estabelecer hábitos de leitura e discussão coletiva entre os professo- } \\
\text { res; } \\
\text { - Reforçar os princípios das teorias que dão sustentação à proposta. }\end{array}$ \\
\hline $\begin{array}{l}\text { Produção e divulgação quinzenal } \\
\text { do Boletim Cresça e Apareça, } \\
\text { contendo diretrizes teórico-prá- } \\
\text { ticas para o trabalho educativo. }\end{array}$ & $\begin{array}{l}\text { - Encaminhar para todos os professores da rede municipal de educação } \\
\text { infantil; } \\
\text { - Compartilhar textos de formação teórica, dicas e sugestões; } \\
\text { - Divulgar boas práticas dos professores. }\end{array}$ \\
\hline $\begin{array}{l}\text { Realização de reuniões mensais } \\
\text { com os diretores dos CER. }\end{array}$ & $\begin{array}{l}\text { - Ampliar o nível de conhecimento dos diretores sobre a Pedagogia } \\
\text { Histórico-Crítica; } \\
\text { - Subsidiar para que os diretores realizem a gerência do Programa } \\
\text { Cresça e Apareça no âmbito da unidade escolar. }\end{array}$ \\
\hline $\begin{array}{l}\text { Formação continuada de direto- } \\
\text { res, professores e agentes educa- } \\
\text { cionais. }\end{array}$ & $\begin{array}{l}\text { - Introduzir e aprofundar os conceitos centrais do referencial adotado; } \\
\text { - Contribuir com a formação teórico-prática, por meio de leituras, dis- } \\
\text { cussões, oficinas e realização das atividades do Cresça e Apareça. }\end{array}$ \\
\hline $\begin{array}{l}\text { Proposição de um esboço da } \\
\text { Proposta Curricular para a rede } \\
\text { de Educação Infantil. }\end{array}$ & $\begin{array}{l}\text { - Propor as bases teóricas, metodológicas e curriculares que enfatizem } \\
\text { ato educativo intencional e comprometido com a aprendizagem e de- } \\
\text { senvolvimento das crianças atendidas nos CER, independentemente da } \\
\text { modalidade, contrapondo-se a práticas assistemáticas e espontaneístas. }\end{array}$ \\
\hline
\end{tabular}

Fonte: Produzida pela autora deste artigo com base nas informações coletadas em Araraquara (2016, p. 4-5) e Barbosa e Pimenta (2018). 
O LAPEI tinha a finalidade de qualificar as práticas pedagógicas no mesmo sentido, sendo composto pela equipe técnica da educação infantil, por diretores, professores e agentes educacionais selecionados dentre os profissionais da rede municipal de educação infantil, bem como por professores do ensino superior e bolsistas do Programa Institucional de Bolsas de Iniciação à Docência (PIBID) da FCLAr. (ARARAQUARA, 2016; BARBOSA; MAZZEU, 2016).

Nessa composição e de seus objetivos, o LAPEI possuía as seguintes incumbências (BARBOSA; MAZZEU, 2016, p. 6289):

\footnotetext{
- Estudo das principais obras dos autores da Psicologia Histórico-Cultural e da Pedagogia Histórico Crítica;

- Levantamento e avaliação das práticas educativas desenvolvidas nas instituições de Educação Infantil;

- Desenvolvimento e elaboração de atividades a serem trabalhadas com as crianças nas instituições educativas tomando como pressuposto as contribuições das teorias acima descritas; - Desenvolver junto aos educadores de novas práticas orientadas pelo princípio da intencionalidade;

- Produzir e distribuir um boletim mensal constituindo-se numa ferramenta de formação continuada dos professores da rede.
}

Ademais, o LAPEI, juntamente com a equipe técnica da educação infantil, também possuía a responsabilidade de avaliar e acompanhar mensalmente as atividades do Cresça e Apareça. (ARARAQUARA, 2016).

Nesse contexto, tornou-se evidente que a finalidade última da parceria SME com a Universidade era a revisão da proposta curricular da educação infantil de Araraquara, mediante formação continuada e demais ações, e o esboço de outra proposta curricular aos CER sob os pressupostos teóricos da Psicologia Histórico-Cultural e da Pedagogia HistóricoCrítica. Contudo, essa nova proposição não foi materializada, assim como as ações de formação e consultoria do Cresça e Apareça foram interrompidas quando na mudança da gestão municipal em 2017 (BARBOSA; PIMENTA, 2018), com exceção do LAPEI. O LAPEI foi apropriado como parte da política municipal de educação infantil da SME.

No tocante à interrupção, é necessário tecermos um comentário quanto ao recorrente fato, não apenas em Araraquara, mas também em âmbito nacional, da interferência desarrazoada das mudanças partidárias sobre a educação, que acaba ficando à mercê de interesses e dinâmicas externas, capazes por exemplo de interromper, como no caso de Araraquara, um trabalho construído ao longo de anos para a educação infantil municipal, sem preparações ou transições tranquilas e adequadas ao melhor interesse da própria rede e das crianças atendidas (e não ao melhor interesse do administrador).

Por outro lado, vale destacarmos certa continuidade nos trabalhos engendrados pelo Cresça e Apareça dentro do município, já que o LAPEI continuou ativo na formação dos profissionais da rede, juntamente com o Centro de Desenvolvimento Profissional de Educadores Paulo Freire (CEDEPE), criado em 2004, na proposição de "ações formativas que contribuam para melhorar ainda mais a ação intencional de professores e agentes educacionais”, conforme perspectiva oficial. (ARARAQUARA, 2017). 


\section{Aspectos Organizacionais}

$\mathrm{O}$ atendimento do CER acontece em período parcial ou integral, sendo de segunda a sexta-feira das $07 \mathrm{~h} 30$ às $17 \mathrm{~h} 00$. No tangente ao período parcial, o horário da manhã é das $07 \mathrm{~h} 30$ às $11 \mathrm{~h} 30$, enquanto a tarde é das $13 \mathrm{~h} 00$ às $17 \mathrm{~h} 00$. A despeito dessa organização, há previsão de flexibilização do horário de entrada e saída nos CER mediante a comprovação de trabalho das mães e/ou responsáveis legais no Regimento Comum (ARARAQUARA, 2011), de modo que a organização dos horários se dá em função do horário de trabalho desses, bem como em função da rotina da unidade. Sobre isso, Assis (2004) menciona o Projeto Municipal Mãe Trabalhadora, que prevê que os CER com demanda de extensão de horário, manifesta pelas mães no momento da matrícula, funcionem em horários especiais para esse atendimento.

Observamos que a preocupação municipal com os responsáveis trabalhadores, notadamente as mães, faz lembrar da tendência histórica da educação infantil no Brasil como favor estatal às mães que trabalhavam e, logo, não tinham tempo de cuidar dos filhos, descolando o direito constitucional da criança a tal atendimento. Tal tendência nos dias de hoje soa ainda mais estranha, tendo em vista que "as mulheres trabalham não apenas por necessidades econômicas. Hoje, o trabalho fora de casa faz parte da vida e da realização pessoal das mulheres" (ASSIS, 2004, p. 108), bem como o direito das crianças à educação já encontra forte respaldo legal. O Regimento Comum do município (ARARAQUARA, 2011) menciona, explicitamente e em praticamente todo o texto, a mãe da criança atendida no CER, pouco se referindo diretamente a figura paterna, abarcando-a muitas vezes na figura genérica do responsável legal. Dada a história da educação infantil, tal constatação se faz relevante, na medida em que a oferta do atendimento às crianças parece ficar circunscrita às necessidades maternas de trabalhar fora de casa, a exemplo da concepção da creche como "mal necessário" (VIEIRA, 1988): "mal", porque revela um suposto desajustamento moral e econômico determinado pela entrada da mulher pobre no trabalho extradomiciliar e, portanto, seu consequente afastamento do convívio familiar e do cuidado da criança; e "necessário", posto que, sem creche, a sobrevivência da criança estaria prejudicada nesse contexto.

O próprio atendimento em período integral oferecido nos CER também se coloca em benefício das "mães e/ou responsáveis legais" trabalhadores. Nas palavras do documento Regimento Comum das Escolas Municipais de Educação Infantil do município, fica dito que:

\footnotetext{
Art. 24. Para se beneficiar do atendimento em período integral, deverá ser apresentado no ato de inscrição, declaração ou comprovante de trabalho da mãe e/ ou responsável legal, a ser confirmado periodicamente, renovado semestralmente, e sempre que houver mudança do local de trabalho. (ARARAQUARA, 2011, p. 13, grifos nossos).
}

Ademais, outra vantagem para os filhos daqueles que trabalham refere-se aos berçários, já que, segundo o mesmo documento, no caso de existir número de crianças excedentes, darse-á prioridade a eles, mediante a comprovação de trabalho independentemente do período a ser atendido (ARARAQUARA, 2011).

Destarte, o forte vínculo estabelecido entre o atendimento nos CER e o trabalho dos responsáveis, especialmente das mães, seja para usufruir do benefício do período integral, seja para alterar horários de funcionamento ou também no caso de preferência de matrícula. 
Vemos com reservas tais disposições, pois, ao se atribuir mais importância ao direito dos trabalhadores (previsto na Constituição Federal de 1988), o município esbarra no próprio direito também constitucional das crianças, quem de fato gozará das vagas nos CER. Além disso, não se pode deixar de mencionar que a própria existência desses benefícios denuncia a falta de vagas e estruturas para atender universalmente as crianças em Araraquara, de modo que o fator "trabalho" acaba sendo a estratégia utilizada para manejá-la.

No município, o referido atendimento organiza-se em 05 etapas nas modalidades creche (Berçário I e II: BI/BII; Classe intermediária: CI), pré-escola ( $3^{\mathrm{a}}, 4^{\mathrm{a}}$ e $5^{\mathrm{a}}$ etapa) e recreação, conforme consta no Regimento Comum (ARARAQUARA, 2011) bem como no artigo $3^{\circ}$, § $1^{\circ}$ da Lei n 4.938/1997 (ARARAQUARA, 1997), com alteração advinda da Lei nº 7.863/2013. (ARARAQUARA, 2013).

Nos berçários (BI e BII), as crianças possuem de 0 a 02 anos e ficam sob a responsabilidade das chamadas agentes educacionais ou educadores (anteriormente berçaristas ou pajens). Os agentes são, segundo Barbosa (2008), profissionais técnicos com formação em nível médio, sem magistério, numa perspectiva de formação em serviço e continuada. (ASSIS, 2004). O projeto curricular denota um caráter integrador e indissociável entre educar, cuidar e brincar aos trabalhos nos berçários (ARARAQUARA, 2011), e Assis (2004) completa que tal integração deve se estruturar em torno da alimentação, do banho, sono e nas atividades de rotina. Conforme a autora, é nesses momentos que se explicita a intenção educativa dos CER nessa etapa. Nesse sentido, tem-se:

\footnotetext{
Todos os momentos e todas as ações que ocorrem no cotidiano dos Berçários deverão ser situações privilegiadas para que as crianças brinquem e participem da função social e educativa do Centro de Educação e Recreação - CER, ou seja, que caminhem em direção à autonomia e independência, a ampliação do conhecimento de si mesma e do mundo. (ARARAQUARA, 2011, p.14, grifos nossos).
}

Nas CI, a mesma perspectiva integradora cuidado-educação-brincadeira orienta essa etapa, com o diferencial de uma professora, graduada em Pedagogia ou Magistério, e uma agente educacional responsável. (ASSIS, 2004).

A seu turno, recreação referenda às crianças em período integral, o que significa que elas passarão 04 horas sob o âmbito da pré-escola e as demais horas na modalidade recreação em conformidade com a faixa etária. De acordo com o Regimento Comum (ARARAQUARA, 2011), o trabalho da recreação se orientará em três eixos, a saber: brincar, passeios e rotina, perpassando cuidar e educar. Assis (2004) explica que as atividades realizadas pela recreacionista (formada em serviço, bem como por formação continuada) privilegiam o lúdico, o esporte, a informação, a higiene, a inserção cultural etc., numa proposta bastante semelhante, em nossa análise, aos primeiros parques infantis de Araraquara. A proposta desses além da assistência médica e nutricional, incluía formas alternativas de recreação numa perspectiva educativa.

A pré-escola, constituída por suas três etapas, é atendida por professores, com formação inicial na área e que também podem participar das formações continuadas oferecidas pela rede municipal. O cuidado e as atividades de rotina também se fazem presentes, mas também se dá uma maior ênfase às atividades educativas mais sistemáticas, como: atividades de expressão corporal, que envolvam habilidades específicas à leitura e escrita, habilidades motoras, por meio dos conteúdos conceituais, procedimentais e atitudinais, como enumera Assis (2004). 
O Regimento Comum (ARARAQUARA, 2011), em seu artigo 27, dispõe que o projeto curricular da pré-escola abarcará o estudo por essas áreas: descoberta de si mesmo, descoberta do meio natural e social e diferentes linguagens.

Diante disso, notamos certas diferenciações que marcam a separação entre creche e préescola, apesar de compartilharem o mesmo ambiente físico e a mesma característica educativa dos CER, mormente quanto aos profissionais responsáveis por cada etapa e quanto à maior ênfase do cuidado (ainda que numa perspectiva educativa) aos BI, BII e CI. Tal constatação também se faz presente no tocante à utilização dos espaços e a frequência de uso nos CER, de acordo com o estudo de Barbosa (2008) e Assis (2004) como veremos mais adiante.

No que concerne à estrutura física do CER, as unidades apresentam substancialmente: 01 sala estruturada; 01 sala de multimeios; 01 sala de recursos; 01 sala de diretoria; 01 depósito de materiais pedagógicos; 01 depósito de materiais de limpeza; 01 sala referência para a Recreação com seus banheiros; 01 sala referência para a CI com seu banheiro; 02 berçários com seus banheiros; 01 lactário; 01 solário; 01 galpão - refeitório; 01 cozinha; 01 depósito de gêneros alimentícios; 01 lavanderia; 01 sanitário para meninos; 01 sanitário para meninas; 01 sanitário para funcionários; 01 sanitário para funcionárias; área livre com tanques de areia e brinquedos. (DIANA, 2015). Algumas diferenciações podem se apresentar em termos estruturais, por exemplo: alguns CER possuem também biblioteca, outros têm sala de repouso, bem como os CER mais antigos (antes parques infantis) não possuem lactários e berçários. (ASSIS, 2004).

Entretanto, enfatizamos o que é característico em todos os CER em Araraquara, em termos físicos e de uso pedagógico, são: sala estruturada, sala de recursos, galpão, sala multimeios, área externa com tanques de areia. Os aludidos espaços são organizados na rede de educação infantil de Araraquara por um sistema de rodízio. (ARARAQUARA, 2011; BARBOSA, 2008; ASSIS, 2004; CAVICCHIA, 1993). Segundo a perspectiva oficial (ARARAQUARA, 2011, p. 15, grifos nossos):

[...] o rodízio se constituirá em um instrumento fundamental para a organização e melhor utilização dos diferentes espaços nos Centros de Educação e Recreação - CERs, favorecendo a execução dos planejamentos, e a intencionalidade da ação educativa na Educação Infantil.

O documento (ARARAQUARA, 2011) justifica que o rodízio otimiza a ocupação de todos os espaços por todos os grupos em momentos distintos e possibilita a diversificação das ações pedagógicas, de acordo com faixa etária e o tipo de atendimento.

Em linhas gerais, na perspectiva municipal, o sistema de rodízio não apenas determina um revezamento de espaços, como também indica, ante a organização deles, um rodízio de atividades a serem realizadas ao longo do período de atendimento: atividades didáticas, lúdicas e de rotina (higiene, refeições, momentos de socialização na chegada das crianças nos CER, guardadas as devidas ênfases e especificidades de cada faixa etária. (BARBOSA, 2008). A título de ilustração, os tanques de areias e a sala de multimeios indicam e favorecem o brincar, o que pode orientar o planejamento dos professores e agentes educacionais nos CER. (ASSIS, 2004).

A despeito da perspectiva oficial, Assis (2004) assevera que, embora em Araraquara o rodízio tenha contribuído para tal finalidade, isso não é garantia da realização de trabalho 
planejado, interessante e diversificado para as crianças, na medida em que, segundo ela, isso também varia e depende das concepções de educação infantil, criança, professor e profissionais da rede em sua prática cotidiana. A partir dessa observação, entendemos que o sistema de rodízio não é determinante, mas bastante relevante na rede municipal da cidade, principalmente se considerar-se o movimento histórico de sistematização das ações pedagógicas, da busca pela unicidade dos centros e da preocupação com a intencionalidade educativa.

O fato de os berçários possuírem salas específicas (os berçários), não os exclui do rodízio, de modo que não ficam restritos a elas, utilizando-se também de outros lugares. (ASSIS, 2004). Na perspectiva oficial, o revezamento de espaços permite que todos os grupos ocupem os mesmos espaços, internos e externos, em diferentes tempos, mas "A faixa etária das crianças determina o tempo de permanência nos diferentes espaços, de modo que os mais velhos ficam mais tempo em sala do que os menores que geralmente permanecem a maior parte do tempo em áreas livres e tanques de areias." (ASSIS, 2004, p. 165).

Os resultados da pesquisa Barbosa (2008) em alguns CER reverberam o excerto acima, sendo-nos bastante elucidativo:

\footnotetext{
Enquanto para as crianças de três anos elas ocupam 10,43\% do tempo, praticamente dedicados a desenhos livres ou atividades plásticas, as crianças de cinco anos têm na realização dessas atividades seu mais alto percentual de tempo, 30, 67\%, cujas atividades caracterizam-se predominantemente por exercícios de coordenação motora fina, reconhecimento e registro de letras ou números, cópia de palavras e em menor proporção, desenhos e atividades plásticas. Por sua vez, essas atividades didáticas também aumentam no cotidiano educativo das crianças de quatro anos $(21,09 \%)$ se comparadas às de três anos e é, previsivelmente, menor em relação ao tempo das crianças de cinco anos. (BARBOSA, 2008, p. 141-142).
}

Isso remete à discussão anterior sobre os indicativos que separam o atendimento da creche e pré-escola sob a ideia de especificidades de atendimentos, diferenciando-se quanto aos profissionais, às ênfases e organizações diárias.

\section{NotA FINAL}

Diante desse percurso histórico, teórico e pedagógico de construção da educação infantil em Araraquara, percebemos que sua trajetória envolveu a complexa finalidade dos CER centrada na formação integral e na predita orientação curricular em termos teóricos, metodológicos e da prática cotidiana por meio dos professores e agentes, haja vista as parcerias históricas com a Universidade ora sob o suporte construtivista, ora da Psicologia Histórico-Cultural e Pedagogia Histórico-Crítica, assim como os preceitos básicos da Pedagogia da Infância identificados por Barbosa nas ações pedagógicas (2008). Mas, certo foi o esforço constante e peculiar da SME em reconhecer, valorizar e buscar o trabalho educativo intencional em seus CER.

Podemos observar pelo estudo realizado que as ações e criações implantadas pelo poder público municipal marcaram o pioneirismo de Araraquara quanto ao reconhecimento do cuidar e do educar numa perspectiva integradora e pedagógica na educação infantil (MASCIOLI, 2012), sendo esta sua grande contribuição para a história da educação desta etapa. 
Esse pioneirismo decorreu da assunção crescente da educação infantil como atribuição do poder público municipal com o CER, cuja criação trouxe à localidade uma nova concepção de atendimento da criança pequena, estruturada e voltada para a melhoria das condições sociais, para o cuidado das necessidades básicas das crianças e, ao mesmo tempo, para o favorecimento de seu desenvolvimento integral e específico. Representou também ação fundamental na tentativa de superação da dicotomia entre creche e pré-escola, ainda presente na história da educação infantil brasileira (MARCELINO, 2004; MARQUEZ, 2006), ao unilas em uma mesma instituição. (MASCIOLI, 2012).

Assim, a partir dessa abordagem, percebemos que o município se distancia da concepção tradicional da educação infantil, em que: a creche é vista como local para manter as crianças em cuidado, enquanto seus responsáveis trabalham; e a pré-escola é interpretada como um ensino preparatório para o ensino fundamental. A história da educação infantil em Araraquara nos mostrou que cuidar e educar - numa perspectiva declaradamente integradora e pedagógica na educação infantil - é sua marca e preocupação desde os anos 1970.

Entretanto, como verificamos em nossa análise, esse distanciamento não é absoluto. Apesar desse avanço, o município se fragiliza nessa junção (cuidar e educar; creche e préescolar) ao não prever, por exemplo, professores para trabalhar nos berçários, como garante para a pré-escola; bem como ter como foco importante de sua organização temporal o atendimento dos responsáveis trabalhadores, especialmente das mães.

Tais dados nos ajudam a explicitar que, embora a educação infantil de Araraquara apresente especificidades e avanços frente à história da educação infantil nacional, ela ainda compartilha de algumas de suas contradições. 


\section{REFERÊNCIAS BiBLIOGRÁFICAS}

ARARAQUARA. Lei no 4938, de 13 de novembro de 1997. Dispõe sobre a instituição do Sistema Municipal de Ensino e dá outras providências. Disponível em: https://leismunicipais.com. $\mathrm{br} / \mathrm{a} / \mathrm{sp} / \mathrm{a} /$ araraquara/lei-ordinaria/1997/493/4938/lei-ordinaria-n-4938-1997-dispoe-sobrea-instituicao-do-sistema-municipal-de-ensino-e-da-outras-providencias . Acesso em: 21 mar. 2018.

ARARAQUARA. Lei $\mathbf{n}^{\mathbf{0}} \mathbf{7 8 6 3}$, de 25 de janeiro de 2013. Dispõe sobre alteração do artigo $3^{\circ}$ da lei no 4938, de 13 de novembro de 1997, que institui o Sistema Municipal de Ensino, e dá outras providências. Tribuna Impressa, Araraquara, 26 jan. 2013, ano 16, exemplar no 4.930.

ARARAQUARA. Secretaria Municipal de Educação. Regimento comum das escolas municipais de educação infantil. Araraquara/SP, 2011, mimeo.

ARARAQUARA. Secretaria Municipal de Educação. Ofício SE n⿳0 138, Araraquara/SP, 2016.

Disponível em: http://www.camara-arq.sp.gov.br/Siave/arquivo?id=145773 . Acesso em: 28 mar. 2018.

ARARAQUARA. Professores da Educação Infantil participam de formação continuada. Araraquara/SP, 2017. Disponível em: http://www.araraquara.sp.gov.br/noticias/professoresda-educacao-infantil-participam-de-formacao-continuada/ . Acesso em: 19 nov. 2018.

ARCE, Alessandra; SILVA, Débora A. S. M.; VAROTTO, Michele. Ensinando Ciências na Educação Infantil. Campinas: Editora Alínea, 2011.

ASSIS, Muriane S. S. de. Representações de professores: elementos para refletir sobre a função da instituição escolar e da professora de educação infantil. 2004, 225f. Dissertação (Mestrado em Educação) - Centro de Educação e Ciências Humanas. Universidade Federal de São Carlos, São Carlos-SP, 2004.

BARBOSA, Eliza M.; PIMENTA, J úlia I. P. B. Luz e sombra no percurso curricular da educação infantil no município de Araraquara. Rev. Espaço do Currículo, João Pessoa, v. 11, n. 2, p. 146153, maio /ago. 2018. Disponível em: http://www.periodicos.ufpb.br/index.php/rec/article/ download/ufpb.1983-1579.2018v2n11.40195/20840 . Acesso em: 15 nov. 2018.

BARBOSA, Eliza M. Educar para o desenvolvimento: críticas a esse modelo em consolidação na educação infantil. 2008, 198 f. Tese (Doutorado em Educação Escolar) - Faculdade de Ciências e Letras, UNESP, Araraquara-SP, 2008.

BARBOSA, Eliza M.; MAZZEU, Francisco J. Os processos de representação da realidade pela criança e a formação do professor de educação infantil. In: CONGRESSO NACIONAL DE FORMAÇÃO DE PROFESSORES, 3; CONGRESSO ESTADUAL PAULISTA SOBRE FORMAÇÃO DE EDUCADORES, 13, Águas de Lindóia. Anais... Águas de Lindóia/SP, UNESP, 2016, p.6287-6298. Disponível em: https://docplayer.com.br/74878126-Os-processos-derepresentacao-da-realidade-pela-crianca-e-a-formacao-do-professor-de-educacao-infantil.html . Acesso em: 15 nov. 2018.

BERTOCHI, Patrícia R. T. O trabalho cotidiano da gestão escolar: percepções dos diretores da educação infantil da rede municipal de Araraquara. Dissertação (Programa de Pós-Graduação Profissional em Educação). Universidade Federal de São Carlos, São Carlos - SP, 2016, 217p. 
BRASIL. Constituição da República Federativa do Brasil, de 05 de outubro de 1988.

Disponível em: http://www.planalto.gov.br/ccivil_03/constituicao/constituicaocompilado.htm . Acesso em: 20 abr. 2017.

CAVICCHIA, Durlei de C. O cotidiano da creche: um projeto pedagógico. São Paulo: Loyola, 1993.

DIANA, Fernando. O brincar nas Formações Continuadas em Serviço oferecidas aos professores da pré-escola. 2015, 170f. Dissertação (Mestrado Profissional em Processos de Ensino, Gestão e Inovação) - Centro Universitário de Araraquara UNIARA, Araraquara - SP.

GOMES, Marineide de $\mathrm{O}$. As creches na trajetória de governos democráticos: a experiência de Diadema/SP (1983-1996). 1996, 160 f. Dissertação (Mestrado em Educação) - Universidade de São Paulo, São Paulo-SP, 1996.

KUENZER, Acácia Z. Desafios teórico-metodológicos da relação trabalho-educação e o papel social da escola In: FRIGOTTO, G. (Org.). Educação e Crise do Trabalho. Petrópolis: Vozes, 1998.

MISSÃO CUMPRIDA: Vaga em creche é garantida. Ministério Público e prefeitura encerram TAC - Termo de Ajustamento de Conduta. Jornal de Araraquara. Araraquara, 10 ago. 2012. Disponível em: http://www.jornaldeararaquara.com.br/index.pas?codmat=56802 . Acesso em: 26 mar. 2018.

MARCELINO, Eliane C. A. O jardim de infância anexo à escola normal de São Paulo: análise do modelo didático-pedagógico. Revista de Iniciação Científica da FFC, v. 4, n. 1, p. 103-116, 2004. Disponível em: http://www2.marilia.unesp.br/revistas/index.php/ric/article/view/74/76 . Acesso em: 12 set. 2018.

MARQUEZ, Christine G. O Banco Mundial e a educação infantil no Brasil. 2006. $215 f$. Dissertação (Mestrado em Educação) - Faculdade de Educação, Universidade Federal de Goiás, Goiânia, 2006.

MASCIOLI, S. A. Z. Cotidiano escolar e infância: interfaces da educação infantil e do ensino fundamental nas vozes de seus protagonistas. 2012, 310 f. Tese (Doutorado em Educação Escolar) - Faculdade de Ciências e Letras, Universidade Estadual Paulista, Araraquara-SP, 2012.

PEREIRA, Mônica. O parque infantil “Leonor Mendes De Barros" da cidade de Araraquara (1941-1971). 2008, 40f. Trabalho de Conclusão de Curso (Graduação) - Departamento de Educação, Universidade Federal de São Carlos, São Carlos, 2008.

PRETO, Mariany C. F. Estudo sobre a caracterização do atendimento escolar da educação infantil no campo, em uma região do Estado de São Paulo. Dissertação (Mestrado em Educação) - Centro de Educação e Ciências Humanas, Universidade Federal de São Carlos, São Carlos -SP, 2016.

ROSEMBERG, Fúlvia. Expansão da educação infantil e processos de exclusão. Cadernos de Pesquisa, n. 107, p. 7-40, 1999. Disponível em: http://www.scielo.br/pdf/cp/n107/n107a01. pdf . Acesso em: 12 out. 2018.

ROSEMBERG, Fúlvia. Organizações multilaterais, estado e políticas de educação infantil. Cadernos de Pesquisa, São Paulo, n. 115, p. 25-64, 2002. Disponível em: http://www.scielo. br/scielo.php?pid=s0100-15742002000100002\&script=sci_abstract\&tlng=pt . Acesso em: 12 out. 2018.

SANTOS, Paula dos. Crianças esperam por vagas nas escolinhas. In. A CIDADE ON 
ARARAQUARA. Cotidiano, 25 set. 2016. Disponível em: https://www.acidadeon.com/ araraquara/cotidiano/NOT,3,7,1198661,Criancas+esperam+por+vagas+nas+escolinhas.aspx . Acesso em: 26 mar. 2018.

SAVIANI, Dermeval. História das ideias pedagógicas no Brasil. $3^{a}$ Ed. Campinas: Autores associados, 2010.

SILVA, Janaina C.; ARCE, Alessandra. Infância, conhecimento e função docente nos documentos do MEC destinados à educação infantil: uma análise a luz da psicologia histórico-cultural. Revista HISTEDBR on-line, Campinas, n. 39, p. 119-135, set. 2010.

VIEIRA, Lívia Maria F. Mal necessário: creches no Departamento Nacional da Criança (19401970). Cadernos de Pesquisa, n. 67, 3-16, nov. 1988. Disponível em: http://publicacoes.fcc. org.br/ojs/index.php/cp/article/view/1215 . Acesso em: 01 out. 2018.ação vinculados à antiga Diretoria de Educação e Cultura do Departamento de Educação, Cultura, Saúde e Promoção Social e não no Departamento de Bem-Estar Social ou Secretaria de Ação Social, como era frequente em outros municípios. (BARBOSA; PIMENTA, 2018, p. 148, grifos nossos). 